\title{
An Effect of Light on Glucose Uptake by the Fungus Blastocladiella britannica
}

\author{
BY EVELYN A. HORENSTEIN AND E. C. CANTINO \\ Department of Botany and Plant Pathology, Michigan State University, \\ East Lansing, U.S.A.
}

(Received 27 April 1964)

\begin{abstract}
When synchronized single-generation cultures of the unicellular water mould Blastocladiella britannica are grown in the presence of white light, they develop into nearly colourless thin-walled sporangia; in the dark they develop into brown pitted thick-walled resistant sporangia. Under these conditions, dry weight/cell increases exponentially at the same rate in light and dark. However, the capacity for uptake of glucose by cells of various ages grown in the dark exceeds that of light-grown cells. Furthermore, just as the course of development along either of the two morphogenetic pathways can be reversed by excluding or supplying light before their respective points of no return, so, too, the rise in their capacities for glucose uptake can be similarly reversed. However, the point of no return for glucose uptake precedes the point of no return for morphogenesis by several hours. The light-sensitive glucose uptake by $B$. britannica may be a factor in determining the ultimate morphology of this organism.
\end{abstract}

\section{INTRODUCTION}

The occurrence of alternate sporangial types among aquatic Phycomycetes is not an unusual state of affairs. The formation of a thick-walled resistant structure is often an integral stage-sometimes the result of sexual fusions and sometimes notin their life histories, and it may serve as a protective device against unfavourable environments (Emerson, 1954; Sparrow, 1960). For the Blastocladiales, one of the triggering agents in such environments is $\mathrm{CO}_{2}$ and/or bicarbonate (Emerson \& Cantino, 1948; Cantino \& Lovett, 1964). On the other hand, the developmental pattern of Blastocladiella britannica appears to be exceptional, for it does not respond to $\mathrm{CO}_{2}$ or bicarbonate; instead, it is visible light which determines its ultimate structural form.

From the progeny of our original single-cell isolate of Blastocladiella britannica (Horenstein \& Cantino, 1961) we selected a substrain (101B) with dual morphogenetic potentialities. When grown on agar media, it produces: $(a)$ in the dark, about 90-100\% brown pitted thick-walled resistant sporangia (RS) with a generation time (g.t.) of about $65 \mathrm{hr}$; $(b)$ in white light, nearly colourless thin-walled sporangia (TWS) with a g.t. of about 30-32 hr. However, neither the absence nor presence of light is required continuously throughout the entire growth period for the genesis of one or the other of these morphological forms. The organism's early stages of development are quite plastic; cells which start their growth in the light, and which are, therefore, on the TWS pathway, can be induced to revert to RS types by eliminating the light. Conversely, calls which start growth in the dark 
(i.e. along the RS pathway) can be transformed into TWS types by exposure to light. In both instances, however, a stage in development is reached beyond which addition or withdrawal of illumination can no longer effect morphogenetic reversal. At this point of no return, the cells have become committed to one pattern or the other. Subsequently we succeeded in demonstrating: $(a)$ the morphological response to light and dark; $(b)$ the reversal of morphogenesis by alteration of the light-anddark regime, using large populations of synchronous single generations of this strain in submerged liquid cultures (Horenstein \& Cantino, 1962).

Up to a point just preceding the end of the generation time of a thin-walled sporangium (TWS), no morphological differences are discernible under the light microscope between it and a dark-grown developing resistant-sporangium (RS) at a corresponding chronological age. Yet, within the next 1-2 hr, the entire protoplast of a thin-walled sporangium is cleaved into hundreds of uninucleate uniflagellate motile spores, and this new generation of cells is then discharged. On the other hand, the thalli growing in the dark have reached only the half-way point in their ontogeny; they continue to enlarge for several hours thereafter and then gradually differentiate into mature resistant sporangia.

$\mathrm{X}$-ray diffraction studies, electron microscopy and chemical analyses (Nabel, 1939; Frey, 1950; Aronson \& Preston, 1960; Fuller, 1960) have established that the cell walls of the Blastocladiales consist predominantly of chitin, and that very little, if any, cellulose is present. Chemical analyses (Cantino, Lovett \& Horenstein, 1957) also suggest that the thickened walls of the resistant sporangium of Blastocladiella emersonii results primarily (Lovett \& Cantino, $1960 a, b$ ) from increased synthesis of chitin, as does that of B. britannica (Horenstein \& Cantino, 1962). Thus, since metabolism of glucose or glucose derivatives must have been involved in the differentiation of the resistant sporangium of $\boldsymbol{B}$. britannica, we undertook studies of glucose uptake to ascertain whether or not light exerted an effect on it.

\section{METHODS}

Growth and preparation of organisms. One-l. Erlenmeyer flasks containing $550 \mathrm{ml}$. Difco PYG broth (1.25 g. peptone, $1 \cdot 25$ g yeast extract, $3 \cdot 0 \mathrm{~g}$. glucose/1.) made up in citric acid $\left(3 \cdot 2 \times 10^{-3} \mathrm{M}\right)+\mathrm{Na}_{2} \mathrm{HPO}_{4}\left(7 \cdot 2 \times 10^{-3} \mathrm{M}\right)$ buffer $(\mathrm{pH} 5 \cdot 8)$ were inoculated with $50 \mathrm{ml}$. of a spore suspension prepared according to Horenstein \& Cantino (1962). In making up media allowance was made for dilution by the inoculum. The final population in the cultures, determined by plate counts, was kept between $7 \times 10^{4}$ and $10^{5}$ cells $/ \mathrm{ml}$. These were incubated at $24^{\circ}$ in a water bath and aerated with water-saturated air at $1500 \mathrm{ml} . / \mathrm{min}$. Light-grown cultures were illuminated from below with $\mathbf{5 0 0}$ f.c. fluorescent white light; dark-grown cultures were covered with aluminium foil.

The entire population in each flask was harvested by filtration, and the cells washed with $600 \mathrm{ml}$. of citric acid + phosphate buffer (see above). In the process, the fungus was concentrated into the bottom of the cone of a filter paper in a glass funnel. The latter was then placed over a calibrated cylinder, a small hole was poked through the bottom of the paper, and the cells (easily dislodged) washed quantitatively into the cylinder with buffer and made up to a desired volume. The density of the final suspension ranged from $0.3 \times 10^{6}$ to $1.4 \times 10^{6}$ cells $/ \mathrm{ml}$. Throughout 
the preceding procedure, cells were readily maintained in suspension and unclumped. Replicate samples were removed for dry-weight determinations $(24 \mathrm{hr}$, $70^{\circ}$, in vacuum oven).

Determination of glucose uptake capacity. Ten and $15 \mathrm{ml}$. samples of the above cell suspension were placed in test tubes at $24^{\circ}$, and the volume adjusted to $19 \mathrm{ml}$. with the citrate + phosphate buffer. At zero time, $1 \mathrm{ml}$. of buffer containing $50 \mu \mathrm{M}$ glucose was added to each tube (this concentration of sugar was selected because higher concentrations yielded no increase in glucose consumption while lower concentrations tended to depress its uptake). A fine stream of air served to keep the contents agitated and the cells suspended throughout the $45 \mathrm{~min}$. incubation. For this period, glucose uptake by such pre-formed cells was not affected by the presence or absence of light; therefore, these incubations were carried out under ordinary light conditions of the laboratory. At the end of the incubation, cells were filtered off and washed with water; cells and filtrates were then frozen.

Glucose was determined with glucose oxidase (Glucostat Reagent from Worthington Biochemical Corp., Freehold, New Jersey, U.S.A.) according to Washko \& Rice (1961). The glucose uptake capacity (GUC), defined as $\mu \mathrm{g}$. glucose consumed/cell during $45 \mathrm{~min}$. incubation at $24^{\circ}$, was calculated from glucose concentrations in the filtrate before and after incubation.

\section{RESULTS AND DISCUSSION}

\section{Effects of the light-dark regime}

In synchronous single-generation cultures of Blastocladiella britannica, the generation time (g.t.) of light-grown thin-walled sporangia (TWS) is defined as that time when about $20 \%$ of the population has developed discharge tubes; at $24^{\circ}$, with population densities between $3 \times 10^{4}$ and $10^{5}$ cells $/ \mathrm{ml}$., it is about $30 \mathrm{hr}$ (Horenstein \& Cantino, 1962). Within 1-2 hr thereafter, all the rest of the cells develop discharge tubes and a few begin to release their spores. The g.t. for dark-grown resistant sporangia (RS) is defined as $65 \mathrm{hr}$; such cells never discharge spores in culture.

When cells are grown continuously in the dark from spores, they can still be induced to form thin-walled sporangia if they are transferred to an illuminated environment at any time up to a critical point of no return; this occurs at $28 \mathrm{hr}$. However, when illumination is delayed until the last possible moment-i.e. until this point of no return is reached-the generation time of the thin-walled sporangia is usually prolonged by a few hr; and, when it is delayed beyond this point, thinwalled sporangia are no longer formed while resistant sporangia appear instead. Thus, on the basis of the combinations tried so far, there are three different regimes of light and dark which yield only thin-walled sporangia, and three which yield only resistant sporangia (Fig. 1). In effect, there appear to be two non-overlapping periods (18-20 $\mathrm{hr}$ and 28-30 $\mathrm{hr}$ ) in the life span of a thin-walled sporangium during which light exerts its sharp effect on morphogenesis. Light is obligatory for formation of thin-walled sporangia only during one or the other of these periods; or alternatively, light must be absent during either one of these two periods if resistant sporangia are to be formed. 


\section{Growth rates in light and dark}

Although the first visible signs of photomorphogenesis are not detectable microscopically until the generation time of a thin-walled sporangium is reached, it was clear from previous reversal work (Horenstein \& Cantino, 1962) and the results described above, that light modifies the cells of Blastocladiella britannica in some manner at some earlier stage in their ontogeny. Since a parameter associated with

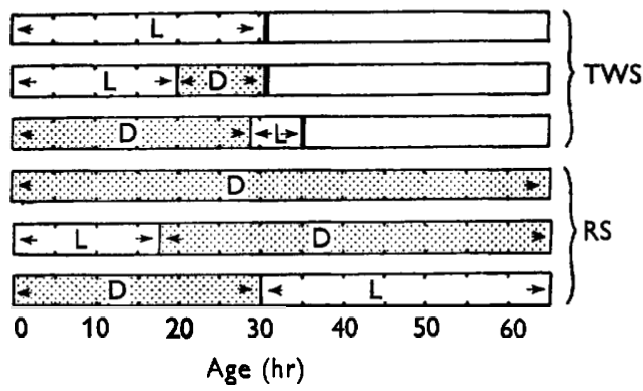

Fig. 1. The effect of exposure during growth to different light-dark regimes upon the nature of cell types finally formed (thin-walled sporangia, TWS, or resistant sporangia, RS) and their generation times (vertical heavy bars) at $24^{\circ}$. See text for details.

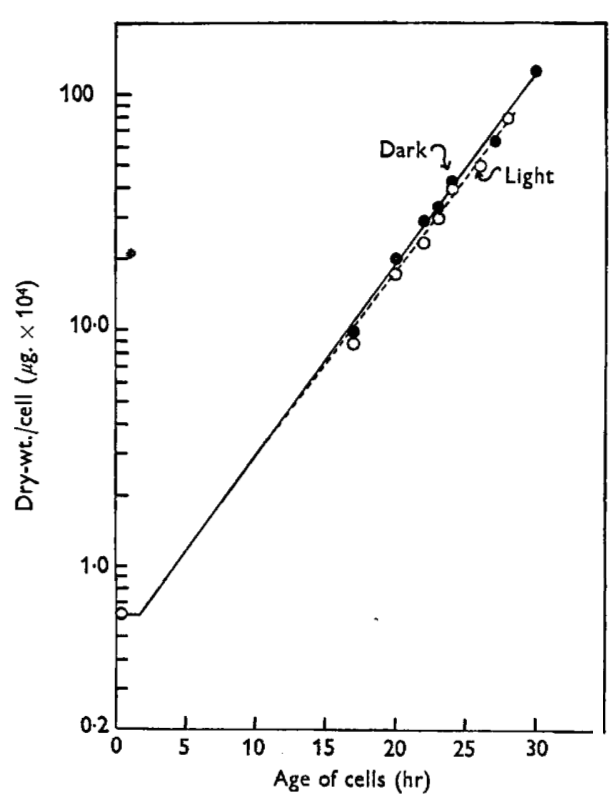

Fig. 2

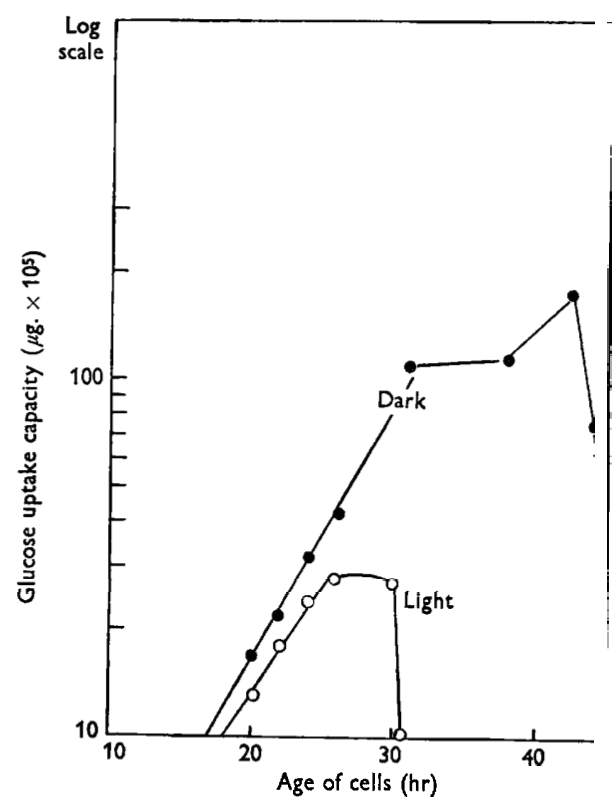

Fig. 3

Fig. 2. The exponential increase in dry wt./cell during growth in the light and dark at $24^{\circ}$. Each point is an average for at least three different cultures, twenty-nine of them light-grown and forty-two dark-grown. Population densities were within the ranges $3-15 \times 10^{4}$ cells $/ \mathrm{ml}$. medium.

Fig. 3. The glucose uptake capacity of light-grown and dark-grown cells at different stages in their development at $24^{\circ}$. 
growth rates might have reflected these changes, a detailed search was made for possible differences in cell weights. However, in both light- and dark-grown cultures, the dry weight/cell increases exponentially at identical rates (following a 1-2 $\mathrm{hr}$ lag after spore inoculation) up to $30 \mathrm{hr}$; i.e. the pattern is not affected by illumination (Fig. 2). These data complement favourably an earlier report (Horenstein \& Cantino, 1962) that the rate of exponential increase in the volume of a growing cell is also independent of light and darkness.

\section{Glucose uptake capacity}

Next, the glucose uptake capacity (GUC) was determined with cells of various ages. In striking contrast to the lack of effect of illumination on the cell dry weight and volume the glucose uptake capacity was affected. The previous history of the celli.e. whether it grew in light or dark-had a definite effect on its capacity to consume glucose under non-growing conditions (Fig. 3). The rate of increase of GUC was slightly greater for dark-grown than for light-grown cells; in both cases, it was exponential up to $26 \mathrm{hr}$ (i.e. $81 \%$ of the generation time for thin-walled sporangia, and $40 \%$ of the generation time for resistant sporangia). At $26 \mathrm{hr}$, the glucose uptake capacity of a light-grown cell levelled off and then fell precipitously just before the completion of its generation-time. A dark-grown cell also exhibited a change in its glucose uptake pattern, although a different one. In this case, the glucose uptake capacity continued to increase up to $30 \mathrm{hr}$, after which it increased at a much lower rate up to about $65 \%$ of the generation time of the resistant sporangia; then, it too decreased sharply.

\section{Reversal of glucose uptake capacity}

Experiments were done to ascertain whether the glucose uptake capacity of a dark-grown cell could be reversed (i.e. reduced) to the glucose uptake capacity of a light-grown cell, just as morphogenesis itself can be reversed. Cultures were grown in the dark for $18 \mathrm{hr}$ (an $18 \mathrm{hr}$ period was selected because this precedes by only a few hours the point of no return for resistant sporangium morphogenesis). The same cultures were then illuminated, and after various additional periods of growth (up to $30 \mathrm{hr}$ ) in the light, the cells were harvested and their glucose uptake capacity determined. Our thesis was this: if light-depressed glucose uptake capacity is a causal factor for the light :nduced differentiation of a thin-walled sporangium, then the effect of light on glucose uptake capacity should occur before the photomorphogenetic response. The results of these experiments on reversal of glucose uptake capacity are shown in Fig. 4, where they are compared with the glucose uptake capacity values for control cultures grown continuously either in light or in dark. It is apparent that with relatively short exposures to light before the point of no return for resistant sporangium morphogenesis, values for glucose uptake capacity approached those of cells grown continuously in the dark for the same total period of time. But with increasing exposures to light, glucose uptake capacity values were progressively depressed and closely approached those of light-grown cells. It should be noted, however (see below), that complete reversal of glucose uptake capacity to the value associated with a thin-walled sporangium should not be expected, because it turned out that $18 \mathrm{hr}$ is just a little beyond the point of no return for glucose uptake capacity itself. 


\section{The point of no return for glucose uptake capacity}

The morphological point of no return for light-grown thin-walled sporangia and dark-grown resistant sporangia has been established (see: Effects of the light-dark regime). The following experiments were designed to define the point of no return for the accumulation in the cell of glucose uptake capacity itself. Cells were grown in the dark for different lengths of time and then transferred to light; after $30 \mathrm{hr}$ of growth, all of them were harvested and their glucose uptake capacities determined.

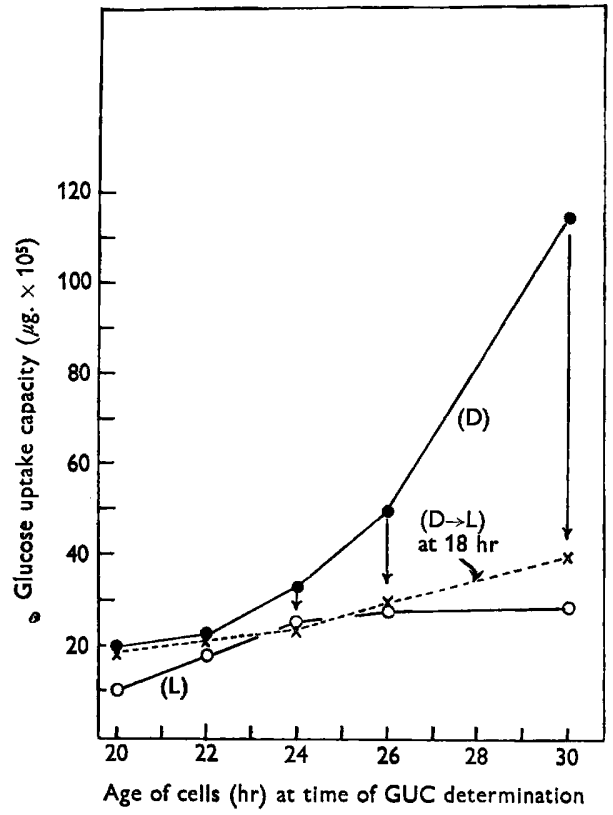

Fig. 4

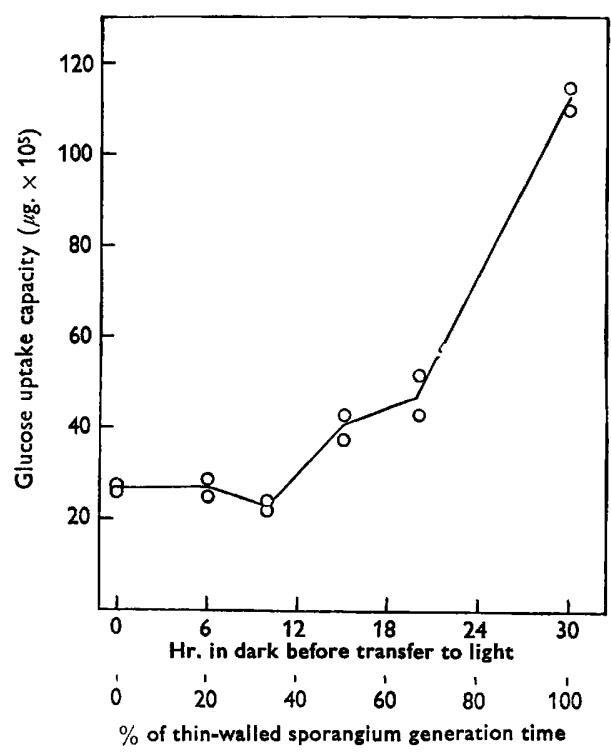

Fig. 5

Fig. 4. The effect of different exposures to light (following growth in the dark for $18 \mathrm{hr}$ ) upon the glucose uptake capacity of cells at different stages in their development at $24^{\circ}$. See text for details.

Fig. 5. The point of no return for the depressing effect of light upon glucose uptake capacity (GUC). See text for details.

The results (Fig. 5) show that when cells were grown from the outset in the dark and then illuminated before $12 \mathrm{hr}$ had elapsed $(40 \%$ of the generation time of a thinwalled sporangium), they retained the same low glucose uptake capacity characteristic of cells grown continuously in the light for $30 \mathrm{hr}$. But once $40 \%$ of the cell's generation time had elapsed, increased exposures to darkness, before providing the dosage of light, resulted in increased values of glucose uptake capacity; these values gradually approached the typically high glucose uptake capacity of a cell grown in the dark throughout its generation time.

The data provided in this paper do not, of course, offer proof that a cause-andeffect relationship exists between the magnitude of glucose uptake capacity and the differentiation of resistant sporangia versus thin-walled sporangia. However, the 
data are consistent with our present hypothesis, namely: $(a)$ that although there is considerable latitude in the glucose uptake capacity which permits a cell to develop into a thin-walled sporangium, a significantly higher minimum value of glucose uptake capacity must be attained by a cell before it can develop into a resistant sporagium; $(b)$ that visible light in some fashion controls this value of the glucose uptake capacity. These notions are currently being tested.

\section{REFERENCES}

Aronson, J. M. \& Preston, R. D. (1960). An electron microscopic and X-ray analysis of the walls of selected lower Phycomycetes. Proc. roy. Soc. B, 152, 346.

CANTino, E. C. \& LovetT, J. S. (1964). Non-filamentous aquatic fungi: model systems for biochemical studies of morphological differentiation. In Adv. Morphogen. 3, 33.

Cantino, E. C., Lovett, J. \& Horenstein, E. A. (1957). Chitin synthesis and nitrogen metabolism during differentiation in Blastocladiella emersonii. Am.J. Bot. 44, 498.

Emerson, R. (1954). The biology of water molds. In Aspects of Synthesis and Order in Grozoth. Ed. by D. Rudnick, 13, 171. Princeton: Princeton Univ. Press.

Emerson, R. \& Cantino, E. C. (1948). The isolation, growth, and metabolism of Blastocladia in pure culture. $A m . J . B o t .35,157$.

Frey, R. (1950). Chitin und Zellulose in Pilzcellwänden. Ber. schreeiz. bot. Ges. 60, 198.

FUlLER, M. S. (1960). Biochemical and microchemical study of the cell walls of Rhizidiomyces sp. Am.J. Bot. 47, 838.

Horenstein, E. A. \& Cantino, E. C. (1961). Morphogenesis in and the effect of light on Blastocladiella britannica sp.nov. Trans. Brit. mycol. Soc. 44, 185.

Horenstein, E. A. \& Cantino, E. C. (1962). Dark-induced morphogenesis in synchronized cultures of Blastocladiella britannica. J. Bact. 84, 37.

LovetT, J. S. \& CANTINo, E. C. (1960a). The relation between biochemical and morphological differentiation in Blastocladiella emersonii. II. Nitrogen metabolism in synchronous cultures. Am.J. Bot. 47, 550.

LovetT, J. S. \& CANTino, E. C. (1960b). The relation between bicarbonate, glucosamine synthetase and chitin synthesis in Blastocladiella. Mycologia, 52, 338.

Nabel, K. (1939). Über die Membran niederer Pilze, besonders von Rhizidiomyces bivellatus, nov. spez. Arch. Mikrobiol. 10, 515.

Sparrow, F. K. Jun. (1960). Aquatic Phycomycetes, 2nd ed. Ann Arbor, U.S.A.: University of Michigan Press.

WASHKo, M. E. \& Rice, E. W. (1961). Determination of glucose by an improved 'Glucostat' procedure. Clin. Chem. 7, 542. 